\title{
Narasin inhibits tumor metastasis and growth of ER $\alpha$-positive breast cancer cells by inactivation of the TGF-ß/SMAD3 and IL-6/STAT3 signaling pathways
}

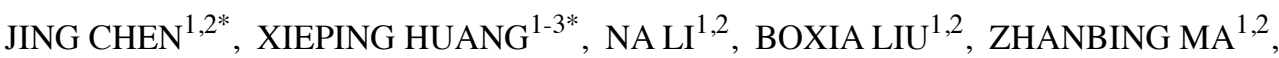 \\ JUN LING ${ }^{1,2}$, WENJUN YANG ${ }^{1,2}$ and TAO $\mathrm{LI}^{4}$
}

\begin{abstract}
${ }^{1}$ School of Basic Medical Sciences, Ningxia Medical University; ${ }^{2}$ Key Laboratory of Fertility Preservation and Maintenance, Ningxia Medical University, Ministry of Education, Yinchuan, Ningxia Hui Autonomous Region 750004; ${ }^{3}$ Department of Dermatology, The Second Peoples's Hospital of Jing Men, Jingmen, Hubei 448000; ${ }^{4}$ Department of Oncology, General Hospital of The Ningxia Medical University, Yinchuan, Ningxia Hui Autonomous Region 750004, P.R. China
\end{abstract}

Received December 27, 2019; Accepted August 27, 2020

DOI: $10.3892 / \mathrm{mmr} .2020 .11624$

\begin{abstract}
Treatment of human estrogen receptor (ER)-positive breast cancer $\left(\mathrm{ER}^{+} \mathrm{BC}\right)$ using conventional chemotherapy remains a challenge and is often ineffective as a result of tumor metastasis. The present study aimed to investigate the ability of narasin, an ionophore antibiotic, to potentially inhibit tumor metastasis and growth in human $\mathrm{ER}^{+} \mathrm{BC}$. Narasin was found to have significant inhibitory abilities on cell proliferation, migration and invasion in $\mathrm{ER}^{+} \mathrm{BC}$ cell lines MCF-7 and T47D compared with the triple-negative BC cell MDA-MB-231. For the in vivo studies, narasin effectively decreased the number of tumor metastasis nodules, tumor volume and weight without apparent toxicity in human MCF-7 nude mouse left ventricle injection tumor metastasis and xenograft models. Mechanistically, it demonstrated that exposure to TGF- $\beta$ or IL- 6 induced the expression of epithelial-mesenchymal transition (EMT) markers in $\mathrm{ER}^{+} \mathrm{BC}$ cell lines. On the contrary, narasin dose-dependently reversed EMT by increasing the expression of E-cadherin and decreasing the expression of $\mathrm{N}$-cadherin, vimentin, $\beta$-catenin and zinc finger E-box-binding homeobox 1 at the protein and gene expression
\end{abstract}

Correspondence to: Dr Tao Li, Department of Oncology, General Hospital of The Ningxia Medical University, 1160 Shengli Road, Yinchuan, Ningxia Hui Autonomous Region 750004, P.R. China E-mail: 1it1979@163.com

Professor Wenjun Yang, School of Basic Medical Sciences, Ningxia Medical University, Ministry of Education, 1160 Shengli Road, Yinchuan, Ningxia Hui Autonomous Region 750004, P.R. China E-mail: ywj007@yeah.net

${ }^{*}$ Contributed equally

Key words: narasin, breast cancer, epithelial-mesenchymal transition, tumor metastasis, tumor growth levels. Gene microarray, molecular docking and western blotting were performed to demonstrate that those protein and gene expression levels are regulated by the inactivation of the TGF- $\beta /$ phosphorylated (p)-SMAD3 and IL-6/p-STAT3 signaling pathways. Taken together, these findings indicated that narasin may be a promising candidate that can be further optimized for the treatment of human $\mathrm{ER}^{+} \mathrm{BC}$.

\section{Introduction}

Breast cancer (BC) is the most commonly diagnosed cancer and the leading cause of death in women worldwide, accounting for $\sim 2.1$ million new cases and 626,679 deaths (1). It is a heterogeneous disease with different histopathological features and therefore has different prognostic outcomes. Among those, $70-80 \%$ of patients with $\mathrm{BC}$ are diagnosed with estrogen receptor (ER)-positive $\mathrm{BC}\left(\mathrm{ER}^{+} \mathrm{BC}\right)(2,3)$.

Metastasis is common in late-stage $\mathrm{BC}$, which is a complicated and multistep process that involves alterations in multiple pathway stages and the accumulation of genetic mutations. During metastasis, cancer cells leave the primary tumor, invade the circulatory and lymphatic system, enter distant organs and form metastases (4). In this process, tumor cells undergo multiple changes that drive their spread, invasion, migration and homing, and eventually cause them to form colonies $(5,6)$. The majority of solid human tumors are of epithelial cell origin, which undergo a complicated process to initiate metastasis and epithelial-mesenchymal transition (EMT) (5-7). During EMT, epithelial cells lose their polarity and adhesion capacity, and become mesenchymal-like cells, which allows them to have migratory and invasive abilities (5-7). Increasing evidence has demonstrated that the TGF- $\beta$ /SMADs, IL-6/STAT3 and PI3K/AKT signaling pathways promote EMT during tumor metastasis $(8-10)$.

Endocrine therapies using selective ER modulators, antiestrogens and aromatase inhibitors are the primary treatment strategy for $\mathrm{ER}^{+} \mathrm{BC}$ (11-13). Although there are a number of drugs used to treat $\mathrm{ER}^{+} \mathrm{BC}$, these drugs are often associated with drug resistance and severe side effects $(14,15)$. Therefore, 
developing more effective medications with fewer side-effects to treat $\mathrm{ER}^{+} \mathrm{BC}$ is urgently required.

Narasin, a carboxylic polyether ionophore isolated from Streptomyces albus, has widely been applied in agriculture as an antibiotic to treat coccidiosis in poultry (16). It is a derivative of salinomycin, which has been confirmed to be a specific inhibitor of cancer stem cells $(17,18)$. Previous studies found that narasin induces apoptosis, inhibits the proliferation of

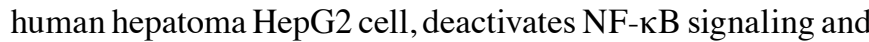
overcomes tumor necrosis factor-related apoptosis-inducing ligand resistance in glioma cells via endoplasmic reticulum stress (19-21). Our previous study confirmed that salinomycin has active antitumorigenic activities in human gastric cancer by suppressing vascular endothelial growth factor receptor 2-mediated angiogenesis (22). However, the role of narasin in cancer treatment and the related molecular mechanisms have not yet been fully elucidated. The present study reported that narasin inhibited proliferation, migration and invasion of human metastatic $\mathrm{ER}^{+} \mathrm{BC}$ cells by inactivating the TGF- $\beta$ /SMAD3- and IL-6/STAT3-mediated EMT signaling pathways in vitro and in vivo. These findings support the possibility of repurposing narasin in the treatment of $\mathrm{ER}^{+} \mathrm{BC}$.

\section{Materials and methods}

Chemicals and reagents. Narasin was purchased from Sigma-Aldrich (Merck KGaA), dissolved in 100\% DMSO to generate a $10 \mathrm{mM}$ solution and stored at $-80^{\circ} \mathrm{C}$ in small aliquots Recombinant human TGF- $\beta$ and IL- 6 were purchased from PeproTech, Inc. Antibodies against phosphorylated (p)-STAT3 (Tyr705; cat. no. 9145; 1:1,000), STAT3 (cat. no. 9139; 1:1,000), p-AKT (Ser473; cat. no. 4060; 1:1,000), AKT (cat. no. 4691; 1:1,000), p-SMAD2 (Ser465/467)/SMAD3 (Ser423/425; cat. no. 8828; 1:1,000), SMAD3 (cat. no. 9523; 1:1,000), $\beta$-catenin (cat. no. ARG52651; 1:800; Arigo Biolaboratories Corp.), ZEB1 (cat. no. ab203829; 1:500; Abcam) and $\beta$-actin (cat. no. M1210-2; 1:10,000; Hangzhou HuaAn Biotechnology Co., Ltd.), as well as an EMT Antibody Sampler kit (cat. no. 9782; 1:1,000) were purchased from Cell Signalling Technology, Inc. All other reagents were acquired from Sigma-Aldrich (Merck KGaA).

Cell culture. Human $\mathrm{ER}^{+} \mathrm{BC}$ cell lines, MCF-7 and T47D, and human triple-negative $\mathrm{BC}$ cell line, MDA-MB-231, were purchased from the American Type Culture Collection. All cells were cultured in DMEM or RPMI-1640 medium supplemented with $10 \%$ fetal bovine serum, and the medium was replaced every $48 \mathrm{~h}$. Cells were maintained in a humidified $37^{\circ} \mathrm{C}$ incubator with $5 \% \mathrm{CO}_{2}$.

Cell viabilityassay. Human BC cells were incubated in a 96-well plate at a density of $4.5 \times 10^{4}$ to $5.5 \times 10^{4}$ cells per well and treated with narasin at a final concentration of $0,1,2.5,5,10 \mu \mathrm{M}$ for $72 \mathrm{~h}$ at $37^{\circ} \mathrm{C}$. Cell viability was determined using an MTS kit (CellTiter 96 Aqueous One Solution Reagent; Promega Corporation), as previously described $(23,24)$. MTS solution $(20 \mu \mathrm{l})$ was added to each well, the plates were incubated for $2 \mathrm{~h}$, and the absorbance was measured at $490 \mathrm{~nm}$ with a microplate reader (Bio-Rad Laboratories, Inc.). All experiments were repeated three times.
Wound healing assay. The wound healing assay was performed as previously described $(23,24)$. Briefly, human $\mathrm{BC}$ cell lines were incubated in 6-well plates and allowed to grow to $80 \%$ confluence. Cells were then washed three times with the medium, scratched with a $200 \mu 1$ pipette tip, and incubated in the growth medium with $10 \%$ FBS and different concentrations of narasin. Images of cells were taken at $24 \mathrm{~h}$ at $\mathrm{x} 40$ magnification with an inverted microscope (TE2000; Nikon Corporation). The migrated cells were counted in three randomly selected fields. Cells in the growth medium without narasin treatment served as the vehicle control. The inhibition percentage was expressed as a percentage of vehicle control (100\%). The assay was repeated three times.

Transwell chamber invasion assay. The cell invasion assay was performed using Matrigel-coated Boyden inserts $(8 \mu \mathrm{m}$; BD Biosciences), as previously described (23,24). Cells in the logarithmic growth phase were digested using trypsin. Subsequently, $150 \mu \mathrm{l}$ serum-free culture medium containing $1 \times 10^{6}$ cells was plated into the upper chamber, and $600 \mu 1$ culture medium containing different doses of narasin was plated into the lower chamber. The assays were performed for $12 \mathrm{~h}$. Invaded cells were fixed with $4 \%$ paraformaldehyde at $4^{\circ} \mathrm{C}$ for $20 \mathrm{~min}$, stained with $0.5 \%$ crystal violet for $10 \mathrm{~min}$ at room temperature, and counted under a light microscope in 4-7 randomly selected fields of view. Three independent experiments were performed in triplicate.

RNA isolation, microarray, bioinformatics analysis and reverse transcription $(R T)$-semi-quantitative $P C R . \mathrm{ER}^{+} \mathrm{BC}$ MCF-7 cells $\left(2 \times 10^{6}\right)$ were seeded in $100-\mathrm{mm}$ tissue culture dishes with or without narasin treatment $(0.05 \mu \mathrm{M})$ for $24 \mathrm{~h}$. TRIzol $^{\circledR}$ reagent (Invitrogen; Thermo Fisher Scientific, Inc.) was used to isolate RNA. The mRNA microarray analysis was carried out with the Affymetrix GeneChip ${ }^{\circledR}$ PrimeView $^{\mathrm{TM}}$ Human Gene Expression Array (Affymetrix; Thermo Fisher Scientific, Inc.), according to the manufacturer's instructions by the Gene Tech Company Limited (Shanghai, China). Data were analyzed in The Database for Annotation, Visualization and Integrated Discovery (DAVID) pathway enrichment analysis for Kyoto Encyclopedia of Genes and Genomes (KEGG) enrichment analysis (25-27) (https://david.ncifcrf.gov/), Search Tool for the Retrieval of Interacting Genes (STRING; https://string-db.org/) and the heatmap package in R (28). The differentially expressed genes (DEGs) were determined based on a false discovery rate threshold of 0.05 .

Total RNA was reverse transcribed to cDNA using the RevertAid First Strand cDNA Synthesis kit (Thermo Fisher Scientific, Inc.). The following temperature protocol was used for reverse transcription: $42^{\circ} \mathrm{C}$ for $60 \mathrm{~min}, 70^{\circ} \mathrm{C}$ for $5 \mathrm{~min}$ and $4^{\circ} \mathrm{C}$ maintenance. PCR was performed using the SuperScript III Platinum One-Step Quantitative RT-PCR System (Thermo Fisher Scientific, Inc.). The following thermocycling conditions were used for qPCR: $94^{\circ} \mathrm{C}$ for $3 \mathrm{~min}$; followed by 35 cycles of $94^{\circ} \mathrm{C}$ for $30 \mathrm{sec}$, annealing temperature for $30 \mathrm{sec}, 72^{\circ} \mathrm{C}$ for $35 \mathrm{sec} ; 72^{\circ} \mathrm{C}$ for $10 \mathrm{~min}$; and maintained at $4^{\circ} \mathrm{C}$. The DNA products were run on a $2 \%$ agarose gel containing ethidium bromide. DNA bands were visualized using an ultraviolet imager and a Gel Imaging Analysis 
System (Bio-Rad Laboratories, Inc.). GAPDH was used as the loading control. The sequences of the primers used for qPCR were as follows: E-cadherin forward, 5'-ACAGGATGGCTG AAGGTGAC-3' and reverse, 3'-TCAGGATCTTGGCTGAGG AT-5'; N-cadherin forward, 5'-GGACCGAGAATCACCAAA TG-3' and reverse, 3'-CCATTAAGCCGAGTGATGGT-5'; vimentin forward, 5'-TCGCCAACTACATCGACAAG-3' and reverse, 3'-GACGCATTGTCAACATCCTG-5'; and GAPDH forward, 5'-AGGTCGGTGTGAACGGATTTG-3' and reverse, 3'-TGTAGACCATGTAGTTGAGGTCA-5'. mRNA expression levels were quantified using GeneSpan (version 7.04.02; SynGene).

Molecular docking analysis. Molecular docking analysis was performed to analyze the binding ability of narasin to the TGF- $\beta$ receptor using Autodock 4.2 (The Scripps Research Institute), as previously described $(23,24)$. TGF- $\beta$ receptor (PDB ID, 3TZM) was obtained from RCSB Protein Data Bank (http://www.rcsb.org/) and processed with UCSF Chimera software (version 1.13.1; National Institutes of Health), which included removal of water molecules, ions and ligands. The molecular structure of hydrophilic narasin was obtained from NCBI (https://www.ncbi.nlm.nih.gov/) without the molecular optimization process.

Western blotting analysis. Western blotting was performed as previously described $(23,24)$. Briefly, cells were harvested and lysed with RIPA buffer (4.25 g NaCl, $3.03 \mathrm{~g}$ Tris, $5 \mathrm{~g}$ SDS, $5 \mathrm{ml} \mathrm{NP}-20,2.5 \mathrm{~g} 10 \%$ sodium deoxycholate, $\mathrm{pH}$ 8.0). Protein concentration was determined using a BCA assay kit (Sigma-Aldrich; Merck KGaA). Samples containing 30-50 $\mu \mathrm{g}$ total proteins were separated via SDS-PAGE on $8-12 \%$ gels, and subsequently transferred to PVDF membranes by electroblotting (Bio-Rad Laboratories, Inc.). Membranes were then blocked with 5\% BSA (Sangon Biotech Co., Ltd.) for $2 \mathrm{~h}$, and then incubated overnight at $4^{\circ} \mathrm{C}$ with the following primary antibodies: p-STAT3, STAT3, p-AKT, AKT, p-SMAD2/SMAD3 and an EMT antibody kit. The next day, the membranes were incubated with the appropriate anti-rabbit (1:2,500; cat. no. A21010; Abbkine Scientific Co., Ltd.), anti-mouse (1:2,500; cat. no. A21020; Abbkine Scientific Co., Ltd.) secondary antibodies for $1 \mathrm{~h}$ at room temperature. After several washes, specifically bound antibodies were visualized using an enhanced chemiluminescence system (Bio-Rad Laboratories, Inc.). Protein expression levels were semi-quantified using Image Lab software (version 5.2.1; Bio-Rad Laboratories, Inc.).

Immunofluorescence (IF) assay. For the IF assay, cultured cells $\left(2 \times 10^{4}\right)$ were treated with the indicated concentrations of narasin for $24 \mathrm{~h}$, followed by stimulation with $100 \mathrm{ng} / \mathrm{ml}$ IL- 6 or $5 \mathrm{ng} / \mathrm{ml} \mathrm{TGF}-\beta$ for $2 \mathrm{~h}$ at $37^{\circ} \mathrm{C}$. Cells were fixed with $4 \%$ paraformaldehyde at $0^{\circ} \mathrm{C}$ for $20 \mathrm{~min}$, permeabilized with $0.1 \%$ Triton $\mathrm{X}-100$, and blocked with $1 \%$ BSA in PBS at room temperature for $1 \mathrm{~h}$. The cells were washed 3 times with PBS after each step, followed by incubation with primary antibodies $(1: 1,000)$ overnight at $4^{\circ} \mathrm{C}$. After thorough washing, the cells were stained with FITC-conjugated goat anti-mouse (1:1,000; cat. no. A21020; Abbkine Scientific Co., Ltd.) or anti-rabbit IgG (1:1,000; cat. no. A22120; Abbkine
Scientific Co., Ltd.). Cells were then washed and incubated with DAPI (Beijing Solarbio Science \& Technology Co., Ltd.) for 5-10 min at room temperature. After the final wash, the samples were mounted with Antifade solution (Beijing Solarbio Science \& Technology Co., Ltd.) and visualized under a fluorescence microscope (DM2000; Leica Microsystems $\mathrm{GmbH}$; magnification, x20).

Xenograft and metastasis assays. A total of 46 four-week-old female BALB/c athymic nude mice (weight, $20 \mathrm{~g}$ ) were obtained from the Experimental Animal Center of Ningxia Medical University. All mouse studies were performed according to animal protocols approved by the Institutional Animal Care and Use Committee of Ningxia Medical University (Yinchuan, China). To measure metastasis, MCF-7-Luc cells $\left(1 \times 10^{5}\right.$; Shanghai Key Regulatory Institute of Biomedical Sciences) were injected into the left ventricle of female BALB/c athymic nude mice (5-7 per group). Mice were treated with narasin [0.5 mg/kg ( $\mathrm{n}=6)$ or $1.5 \mathrm{mg} / \mathrm{kg}(\mathrm{n}=5)$; i.p.] or DMSO (control group; $n=7$ ) every 2 days for 50 consecutive days. The IVIS detection system (Caliper Life Sciences) was used to detect tumor growth and metastasis.

For the xenograft assays, MCF-7 cells $\left(1 \times 10^{7}\right.$ cells per mouse; resuspended in compete medium) were subcutaneously implanted into the axilla of the mice. When tumors reached $\sim 100 \mathrm{~mm}^{3}$, the mice were randomly divided into three groups $(\mathrm{n}=9)$ and injected with narasin $(0.5$ or $1.5 \mathrm{mg} / \mathrm{kg})$ or DMSO (control group) every 2 days for 2 consecutive weeks (14 days). After 2 weeks of treatment, the maximal tumor volume was $1,400 \mathrm{~mm}^{3}$. Then, the mice were euthanized, and tumor tissues were harvested, weighed and photographed. Mice were first anesthetized with $2 \%$ pentobarbital $0.2 \mathrm{ml}(20 \mathrm{mg} / \mathrm{kg} / \mathrm{per}$ mouse) by intraperitoneal injection, and then euthanized by cervical dislocation. Cessation of breathing and heartbeat was used to confirm death. There were no accidental deaths during this experiment.

All mice were kept in specific-pathogen-free animal laboratories at Ningxia Medical University, air purification degree was at least 10,000 grade according to the standard requirements, ammonia concentration $\leq 14 \mathrm{mg} / \mathrm{m}^{3}$, temperature was $18-29^{\circ} \mathrm{C}$, daily temperature difference was $\leq 3^{\circ} \mathrm{C}$, relative humidity was $40-70 \%$, air flow speed $\leq 0.18 \mathrm{~m} / \mathrm{sec}$, and room air pressure gradient 20-50 Pa. There was a total of 6 mice in each cage, they were fed and given water regularly every day, and the cage was cleaned every 3 days.

Histology and immunohistochemistry. Tumor tissues were removed, fixed with $10 \%$ formaldehyde at room temperature overnight, and embedded in paraffin (0.4-0.5 mm-thick sections) for immunohistochemical staining analysis to detect the expression of CD31. Sections were blocked with $30 \%$ sheep serum (JinJiang ZhongYi JinQiao Machinery Co.,Ltd.) at room temperature for $1 \mathrm{~h}$. Subsequently, sections were incubated with an anti-CD31 primary antibody (1:500; cat. no. ab134168; Abcam) at $4{ }^{\circ} \mathrm{C}$ overnight. Following primary incubation, sections were incubated with a HRP-conjugated secondary antibody (1:400; cat. no. A21020; Abbkine Scientific Co., Ltd.) for $1 \mathrm{~h}$ at room temperature. Images were taken using a Leica DM4000 B photo microscope (magnification, $\mathrm{x} 400$; Leica Microsystems $\mathrm{GmbH}$ ). 
A

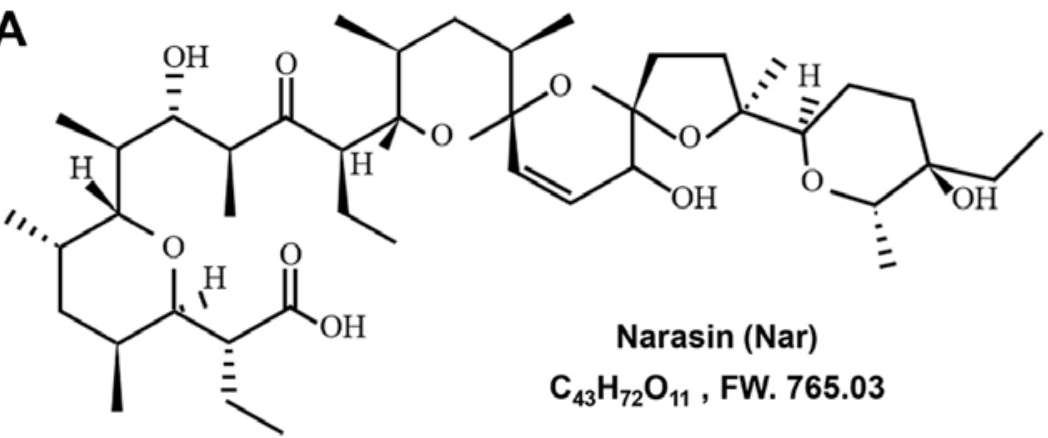

\begin{tabular}{|c|c|}
\hline Cell lines & $\mathrm{IC}_{50}(\mu \mathrm{M})$ \\
\hline MCF-7 & $2.219(1.663 \pm 2.962)$ \\
\hline T47D & $3.562(3.177 \pm 3.994)$ \\
\hline MDA-MB-231 & $11.760(8.393 \pm 16.48)$ \\
\hline
\end{tabular}

B

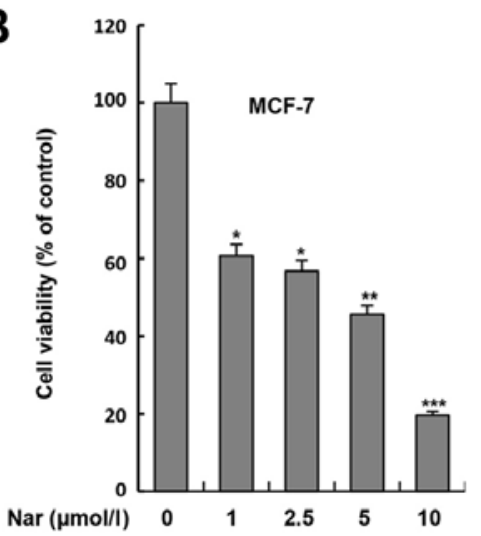

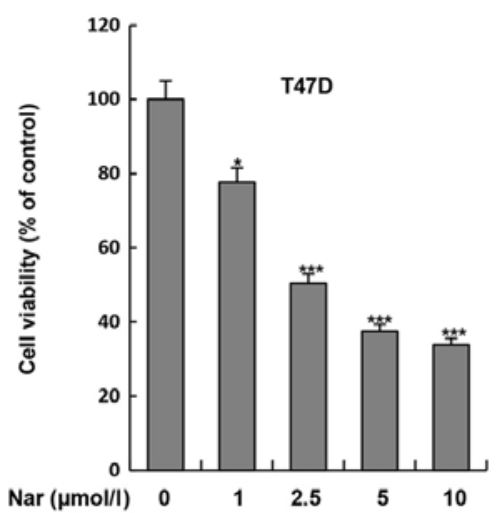

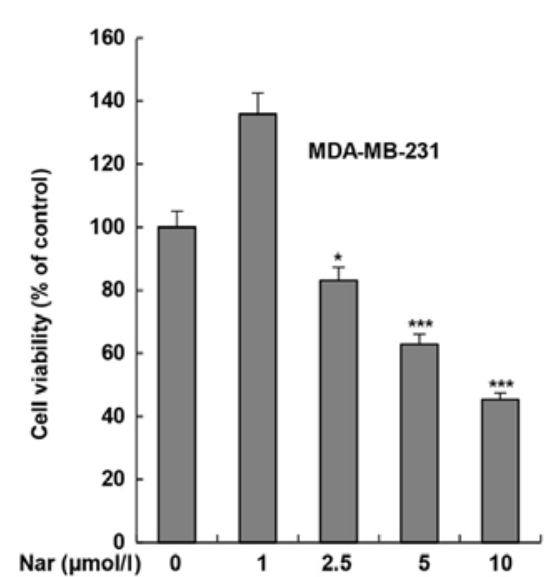

Figure 1. Effect of narasin on breast cancer cell viability. (A) Chemical structure of narasin. (B) Narasin significantly inhibited the cell viability of MCF-7, T47D and MDA-MB-231 cells, with respective $\mathrm{IC}_{50}$ values of $2.219(1.663 \pm 2.962), 3.562(3.177 \pm 3.994)$ and $11.76(8.393 \pm 16.48) \mu$ mol/1 $(\mathrm{P}<0.01)$. The data is presented as the mean $\pm \mathrm{SD}$ of three independent experiments performed in triplicate. ${ }^{*} \mathrm{P}<0.05,{ }^{* * *} \mathrm{P}<0.01,{ }^{* * *} \mathrm{P}<0.001$ vs. the untreated group.

Statistical analysis. Statistical analyses were performed using GraphPad Prism software (version 6.0; GraphPad Software, Inc.). Comparisons among groups were analyzed using one-way ANOVA followed by a Dunnett's test. Data are presented as the mean $\pm \mathrm{SD}$. All experiments were repeated three times. $\mathrm{P}<0.05$ was considered to indicate a statistically significant difference.

\section{Results}

Narasin inhibits $B C$ cell viability. To determine the effect of narasin on BC cells, two $\mathrm{ER}^{+} \mathrm{BC}$ cell lines, MCF-7 and T47D, and one triple-negative BC cell line, MDA-MB-231, were treated with narasin at various concentrations for $72 \mathrm{~h}$. Cell viability was assessed using the MTS cell viability assay kit. As shown in Fig. 1B, narasin significantly inhibited cell viability after treatment with different concentrations of narasin $(1-10 \mu \mathrm{M})$ for $72 \mathrm{~h}$, with a half-maximal inhibitory concentration $\left(\mathrm{IC}_{50}\right)$ of $11.76 \mu \mathrm{M}$ in MDA-MB-231 cells. However, lower concentrations of narasin significantly reduced the viability of MCF-7 and T47D cells, with $\mathrm{IC}_{50}$ values of 2.219 and $3.562 \mu \mathrm{M}$, respectively. Therefore, the data suggested that narasin may have increased inhibitory effects on MCF-7 and T47D ER ${ }^{+} \mathrm{BC}$ cell lines compared with MDA-MB-231 triple-negative $\mathrm{BC}$ cell line.

Narasin inhibits cell migration and invasion by suppressing $E M T$ in $E R^{+} B C$ cells. Cell migration and invasion are essential steps in metastasis. Thus, the effect of narasin on the migration of $\mathrm{BC}$ cells was investigated using a wound healing assay. Of note, it was found that narasin concentrations ranging from 2.5 to $5 \mu \mathrm{M}$ could inhibit the migration of MDA-MB-231 cells. Whereas, narasin at concentrations between 0.005 and $0.05 \mu \mathrm{M}$ significantly inhibited the migration of MCF-7 and T47D cells in a dose-dependent manner (Fig. 2A). The Transwell invasion assay further revealed that narasin dose-dependently suppressed the invasive ability of $\mathrm{BC}$ cells in a similar manner (Fig. 2B). The concentrations of narasin used in the migration and invasion experiments did not affect cell viability (Fig. 2A and B). Thus, this indicated that narasin can significantly inhibit the migration and invasion of $\mathrm{ER}^{+} \mathrm{BC}$ cells at lower concentrations due to inhibition of cell migration rather than inhibition of cell viability. Collectively, these findings suggested that narasin may be a candidate drug for $\mathrm{ER}^{+} \mathrm{BC}$ treatment.

EMT is considered to be the initial and critical step towards the metastasis of cancer cells (29). To explore the potential regulatory mechanisms of narasin in migration and invasion of $\mathrm{ER}^{+}$ BC cells, the expression of commonly known EMT-associated biomarkers, including E-cadherin, $\mathrm{N}$-cadherin and vimentin, were examined by RT-semi-quantitative PCR and western blotting. At concentrations between 0.005 and $0.05 \mu \mathrm{M}$, narasin downregulated the expression of mesenchymal markers (N-cadherin and vimentin), and upregulated the expression of epithelial cell marker E-cadherin in MCF-7 cells (Fig. 2C). Moreover, the EMT transcription factors $\beta$-catenin and zinc finger E-box-binding homeobox 1 (ZEB1) were downregulated by narasin compared with the control 
A
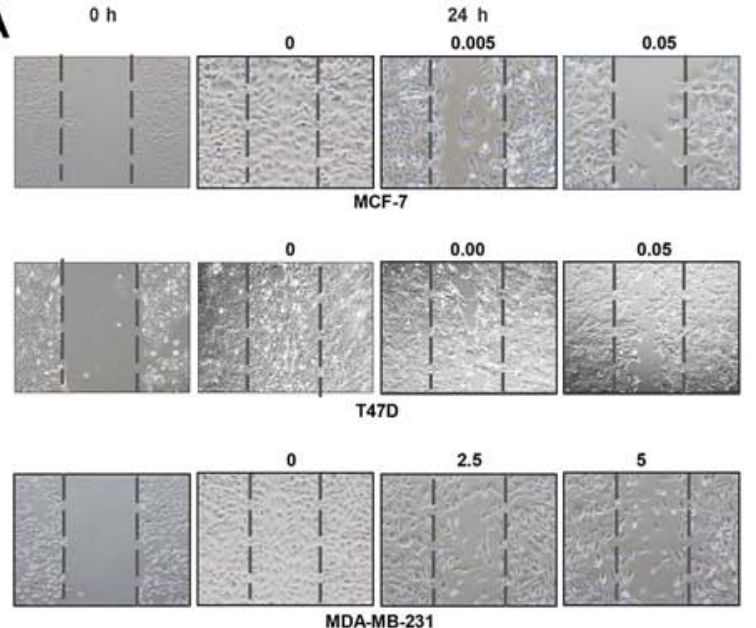

B
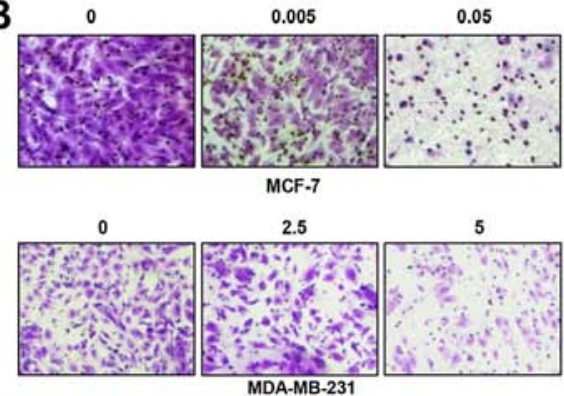
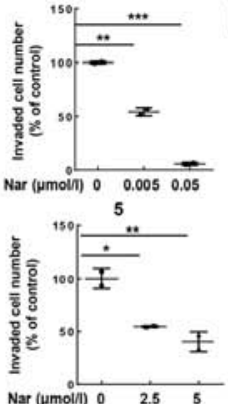
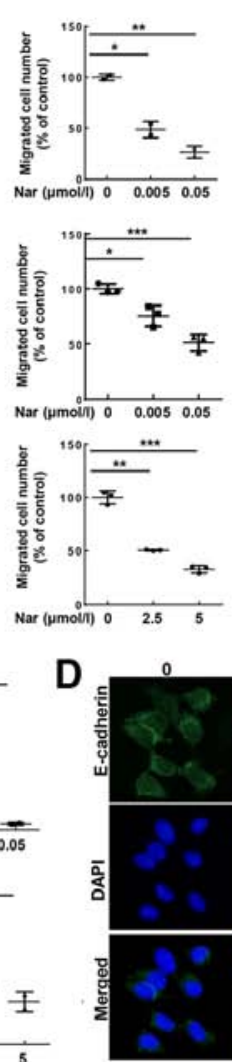

C
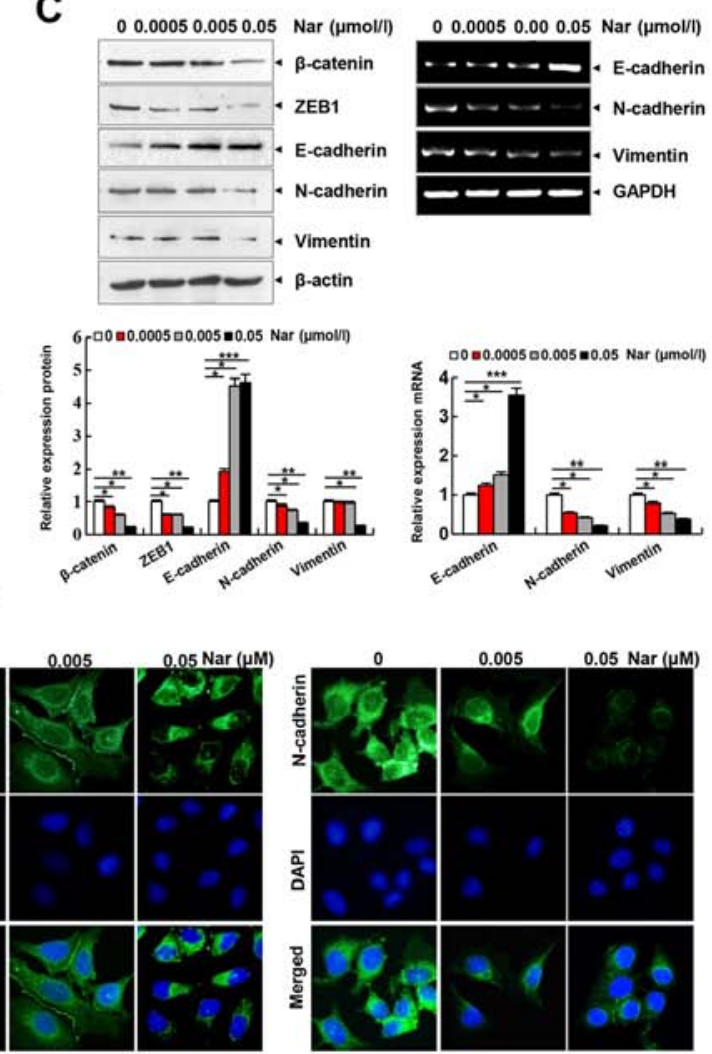

Figure 2. Narasin inhibits BC cell migration and invasion and reverses the EMT phenotype in vitro. (A) Wound healing assay. BC cells were seeded into 6-well plates, a wound was created after the cells reached $100 \%$ confluence, and then different concentrations of narasin were added. Images were acquired after $24 \mathrm{~h}$. (B) Invasion assay. MDA-MB-231 and MCF-7 cells were seeded into the upper chambers of Transwell inserts precoated with Matrigel. After $24 \mathrm{~h}$ of incubation, images were obtained. (C) Following treatment with narasin for $24 \mathrm{~h}$, EMT-related markers were probed by western blotting. MCF-7 cells were treated with narasin for $24 \mathrm{~h}$ and then analyzed for EMT-related marker mRNA expression by reverse transcription-semi-quantitative PCR. (D) MCF-7 cells were treated with narasin for $24 \mathrm{~h}$, and the levels of $\mathrm{N}$-cadherin (green) and E-cadherin (green) were detected by immunofluorescence. Nuclei were stained with DAPI (blue). Scale bar, $40 \mu \mathrm{m} .{ }^{*} \mathrm{P}<0.05,{ }^{* *} \mathrm{P}<0.01,{ }^{* * * *} \mathrm{P}<0.001$. BC, breast cancer; EMT, epithelial-mesenchymal transition; ZEB1, and zinc finger E-box-binding homeobox 1 .

(Fig. 2C). Consistent with this result, an IF assay confirmed that exposure to narasin reversed EMT, as indicated by the decreased membrane-localized $\mathrm{N}$-cadherin and increased E-cadherin (Figs. 2D and S1A and B). These results confirmed that narasin had inhibitory effects on the migration and invasion of $\mathrm{ER}^{+} \mathrm{BC}$ cells by impairing the process of EMT.

Narasin inhibited TGF- $\beta / S M A D 3$ and IL-6/STAT3 signaling in $E R^{+} B C$ cells. A number of reports have demonstrated that human BC cell line MCF-7 is a more suitable model for studying pre-clinical $\mathrm{ER}^{+} \mathrm{BC}$ in vitro and in vivo (30-32). Therefore, to identify the potential mechanisms of narasin-mediated inhibition of $\mathrm{ER}^{+} \mathrm{BC}$ metastasis and proliferation, the $\mathrm{ER}^{+}$ breast cancer line, MCF-7, was chosen to investigate the gene expression profiles involved in the inhibitory effects of narasin by conducting a microarray analysis. Pathway enrichment analysis, an analysis that maps genes to the KEGG pathways (25-27), revealed the involvement of several key signaling pathways, including 'TGF- $\beta$ signaling pathway', 'mTOR signaling pathway', 'JAK-STAT signaling pathway', 'p53 signaling pathway' and 'HIF-1 signaling pathway', which play essential roles in tumor progression and metastasis (Fig. 3A and B). Carcinogenic signaling networks are usually represented as crosstalk between multiple signaling pathways, rendering single protein measurements ineffective in predicting complex cellular responses to drugs. Further enrichment analysis was performed to predict the underlying interaction network based on the DEG profiles (33). The data showed that there were some interactions between these signaling pathways (Fig. 3B and C). Then, the protein-protein interaction networks were examined using data from the STRING database. The results showed that the DEGs of signaling pathways formed tightly connected networks (Fig. 3C), suggesting that these signaling pathways work as a functional module at the protein level. Essential genes that are involved in the function of TGF- $\beta$ and JAK/STAT3 signaling, including 'SMAD3' and 'STAT3', are highlighted in Fig. 3C, and were significantly downregulated by narasin treatment in the presence of $0.05 \mu \mathrm{M}$ in the heatmap (Fig. 3D). Further pathway analysis of these DEGs revealed several pathways that were affected by narasin inhibition. Among these pathways we chose to focus on the top-ranked TGF- $\beta /$ SMAD3 and IL-6/STAT3 signaling pathways.

Effect of narasin on TGF- $\beta / S M A D 3-$ mediated EMT in $E R^{+}$ $B C$ cells. To further explore whether narasin regulated the TGF- $\beta$ /SMAD3 signaling pathway in $\mathrm{ER}^{+} \mathrm{BC}$ cells (34), the effect of narasin on SMAD2/3 phosphorylation, which 
A

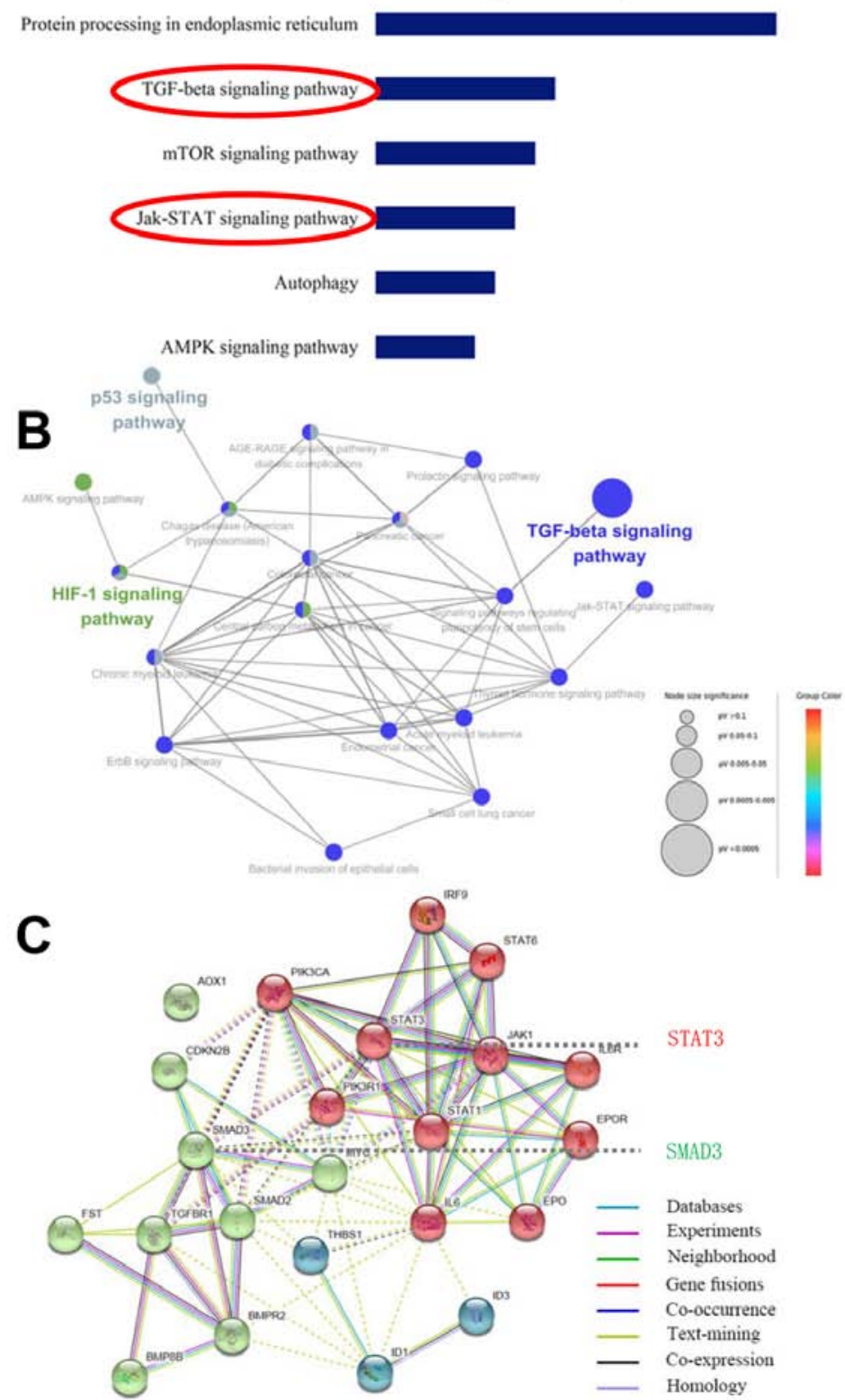

D

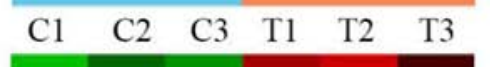

Figure 3. Differential gene profiling in narasin-treated vs. control BC cells by RNA microarray. (A) KEGG pathway analysis by functional enrichment in the PPI network $(\mathrm{P}<0.001)$. In the case of a large number of samples, the difference ratio is not the only way to determine whether a gene is differentially expressed, other statistical parameters can also be combined (such as P-value and Q-value), so FDR $<0.05$ and $\mathrm{P}<0.001$ were both used to reduce false positive rate. (B) KEGG pathway interaction network. (C) KEGG pathways and the PPI network. (D) Hierarchical clustering heat map of KEGG pathways in untreated group (C1-C3) and treated group (T1-T3) in BC cells. BC, breast cancer; KEGG, Kyoto Encyclopedia of Genes and Genomes; PPI, protein-protein interaction.

is a crucial mediator of TGF- $\beta$ /SMAD3 signaling (35-39), was examined. Narasin at tested concentrations (0.005 to $0.05 \mu \mathrm{mol} / 1)$ inhibited SMAD2/3 phosphorylation without TGF- $\beta$ in a dose-dependent manner in $\mathrm{ER}^{+} \mathrm{BC}$ cell lines MCF-7 (Fig. 4A) and with or without TGF- $\beta$ in a dose-dependent manner in $\mathrm{ER}^{+} \mathrm{BC}$ cell lines MCF-7 and T47D (Fig. 4B-C). The results showed that TGF- $\beta$ triggered SMAD2/3 phosphorylation in MCF-7 and T47D cells (Fig. 4B and C). Treatment with narasin $(0.005$ to $0.05 \mu \mathrm{mol} / \mathrm{l})$ notably inhibited TGF $\beta$-induced SMAD2/3 phosphorylation in a dose-dependent manner in MCF-7 and T47D cells without affecting total SMAD2/3 expression (Fig. 4B and C).
To explore the interaction between narasin and the TGF- $\beta$ receptor, a molecular docking experiment was performed using Autodock. The optimized binding model of narasin with the TGF- $\beta$ receptor is shown in Fig. 4D. The narasin molecule was bound to the ATP binding pocket of the TGF- $\beta$ receptor and was stabilized by hydrogen bonds and hydrophobic interactions. Hydrogen bonds between the amino of Lys232 and the hydroxyl of narasin, and guanine of Arg294 with oxygen of narasin, were observed between the receptor and ligand, which can significantly increase the binding ability. Moreover, the hydrophobic interaction, formed by ALKYL 1 groups or aromatic ring of Asp351, His285, Asp290, Tyr295, stabilized 


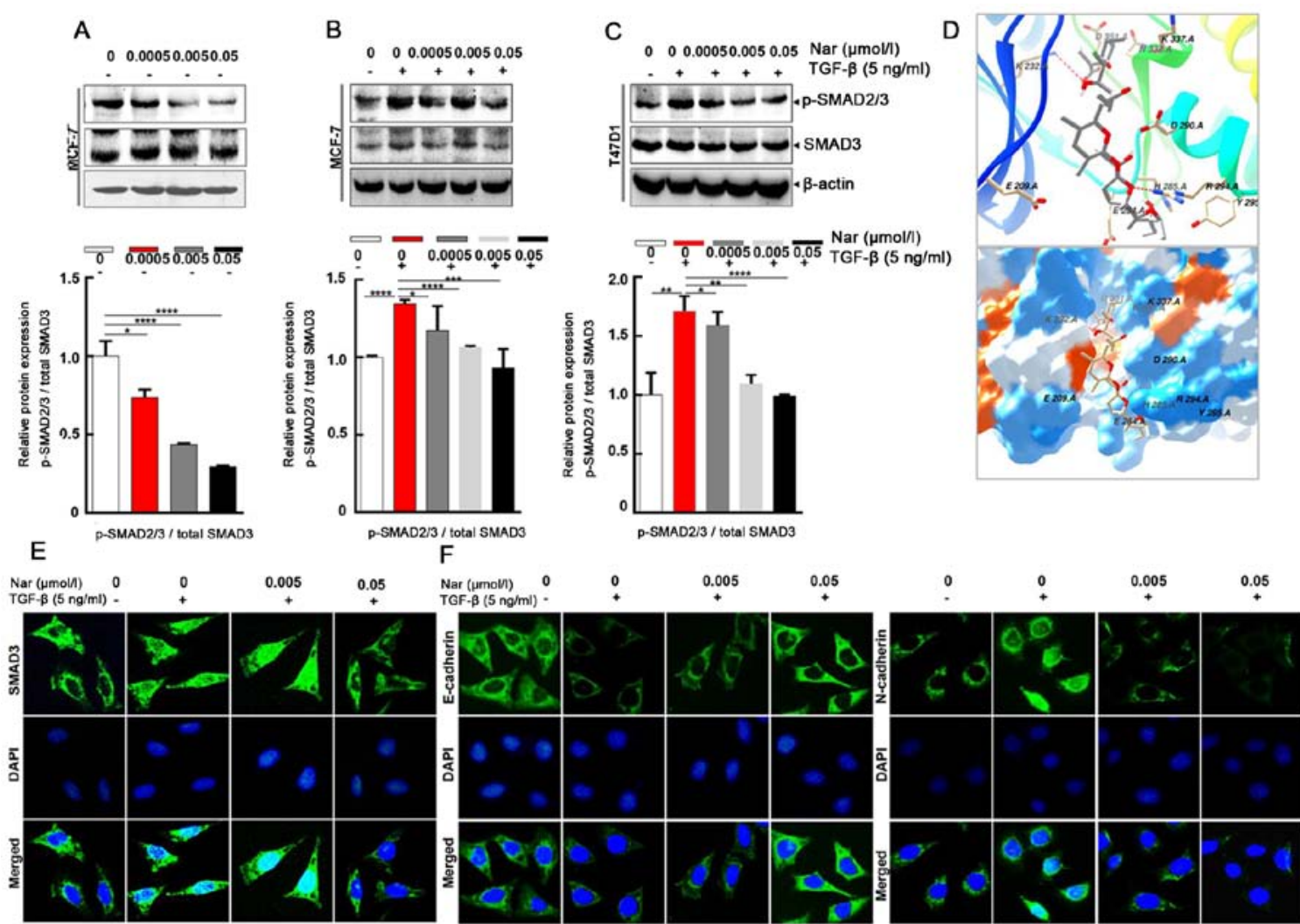

Figure 4. Narasin inhibits TGF- $\beta$-induced SMAD2/3 phosphorylation and epithelial-mesenchymal transition in breast cancer cells. (A-C) Western blotting revealed that treatment with narasin inhibited SMAD2/3 phosphorylation (A) without TGF- $\beta$ stimulation in MCF-7 cells, and with TGF- $\beta$ stimulation in (B) MCF-7 and (C) T47D cells. (D) Autodock software was used to construct a binding model of narasin with the TGF- $\beta$ receptor. (E) IF analysis of SMAD3 MCF-7 cells were treated with various concentrations of narasin for $24 \mathrm{~h}$, stained for SMAD3 (green), counterstained with DAPI (blue), and then observed using a Leica fluorescence microscope. (F) IF analysis of E-cadherin (green) and N-cadherin (green) in MCF-7 cells. The results are from three independent experiments with similar results. ${ }^{*} \mathrm{P}<0.05,{ }^{* *} \mathrm{P}<0.01,{ }^{* * *} \mathrm{P}<0.001,{ }^{* * * * *} \mathrm{P}<0.0001$. IF, immunofluorescence; $\mathrm{p}-$, phosphorylated.

the binding complex in aqueous solution. Hydrophilic interactions between the protein and ligand, which included Lys337, Arg338, Glu284 and Glu209, impacted the molecular chemical conformation of the ligand. These three types of molecular interactions promoted the biological function of narasin to inhibit tumor cell proliferation and metastasis.

The SMAD2/3 complex translocates into the nucleus to regulate the expression of target genes with other DNA-binding transcription factors $(40,41)$. Therefore, IF staining was used to verify the effect of narasin on SMAD3 nuclear translocation in $\mathrm{ER}^{+} \mathrm{BC}$ cells. The results showed that narasin suppressed TGF- $\beta$-induced SMAD3 nuclear translocation in a concentration-dependent manner, with the effective inhibition concentration at 0.005 to $0.05 \mu \mathrm{mol} / 1$ (Figs. 4E and S1C). To examine whether TGF- $\beta$-induced EMT was suppressed by narasin, the TGF- $\beta$-induced expression of E-cadherin and $\mathrm{N}$-cadherin was examined by IF staining in MCF-7 cells.

Of note, MCF-7 cells treated with $5 \mathrm{ng} / \mathrm{ml}$ TGF- $\beta$ led to a significant reduction in epithelial phenotype marker E-cadherin and an increase in the mesenchymal phenotype marker N-cadherin (Figs. 4F and S1D and E). However, cells exposed to narasin $(0.005$ to $0.05 \mu \mathrm{mol} / \mathrm{l})$ showed a dose-dependent increase in the expression of E-cadherin and a decrease in the expression of $\mathrm{N}$-cadherin compared with the TGF- $\beta$ only group (Fig. 4F). Collectively these results indicated that narasin could inhibit the phosphorylation of SMAD3, block the binding of the TGF- $\beta$ receptor with its ligand, and thus inactivate the downstream SMAD2/3-mediated EMT signaling pathway.

Effect of narasin on IL-6/STAT3 signaling-mediated EMT in $E R^{+} B C$ cells. Aside from the TGF- $\beta /$ SMAD signaling-mediated EMT process, STAT3 may also directly mediate EMT in cancer metastasis $(9,42)$. IL-6 is a direct upstream mediator of p-STAT3. In the present study, the effect of narasin on IL-6-induced STAT3 phosphorylation was investigated. The results showed that $100 \mathrm{ng} / \mathrm{ml}$ IL- 6 notably upregulated STAT3 phosphorylation in $\mathrm{ER}^{+} \mathrm{BC}$ cells, and that $0.05 \mu \mathrm{mol} / 1$ narasin effectively inhibited STAT3 phosphorylation in MCF-7 and T47D cells without affecting total STAT3 expression (Fig. 5A). As shown in Fig. 5A, with or without IL-6, narasin (0.005 to $0.05 \mu \mathrm{mol} / \mathrm{l})$ also inhibited AKT phosphorylation and did not affect total AKT expression. Constitutive or inducible phosphorylation at Tyr705 of STAT3 is vital for promoting the biological functions of STAT3, including dimerization and cytoplasmic-to-nuclear translocation of STAT3. It was found that narasin inhibited IL-6-induced STAT3 nuclear accumulation (Figs. 5B and S1F), with the maximum inhibition observed at 0.005 to $0.05 \mu \mathrm{mol} / 1$.

To further determine whether narasin suppressed IL-6-induced EMT, the IL-6-induced expression and distribution of E-cadherin and $\mathrm{N}$-cadherin were examined by IF staining in MCF-7 cells. Treatment with IL-6 decreased the expression of E-cadherin and increased the expression 
A

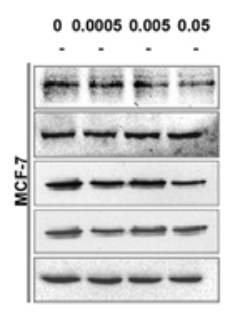

$0 \quad 00.00050 .0050 .05$

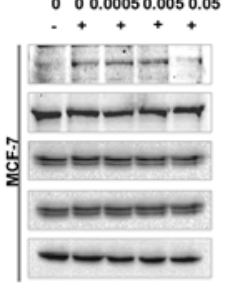

$00.00050 .0050 .05 \mathrm{Nar}(\mu \mathrm{mol} / \mathrm{l})$ $++++\quad \mathrm{LL}-6(100 \mathrm{ng} / \mathrm{ml})$

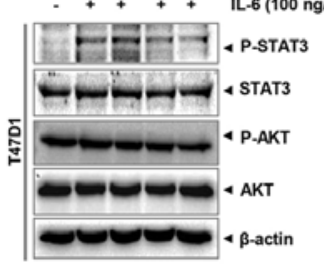

D

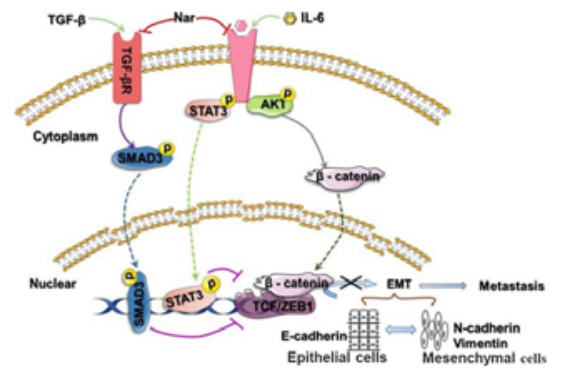

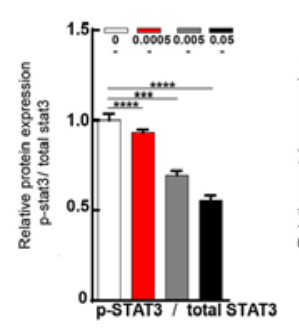
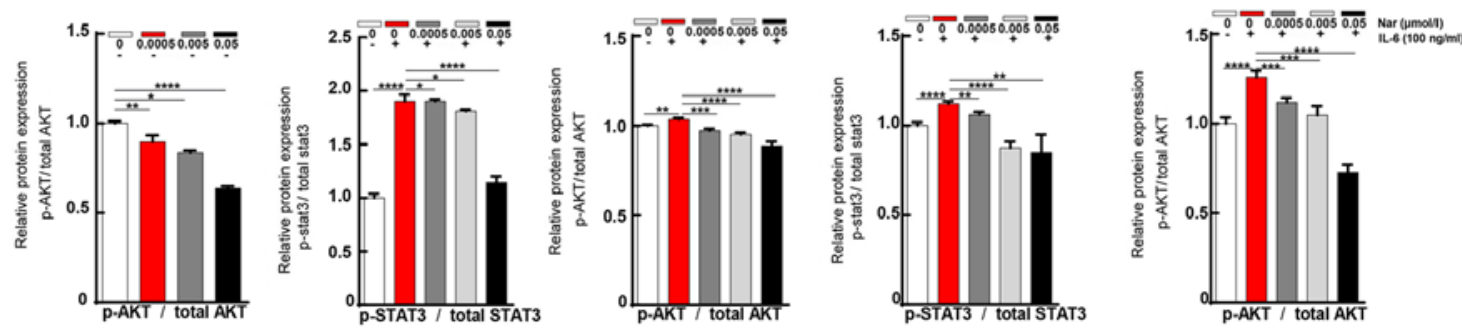

B
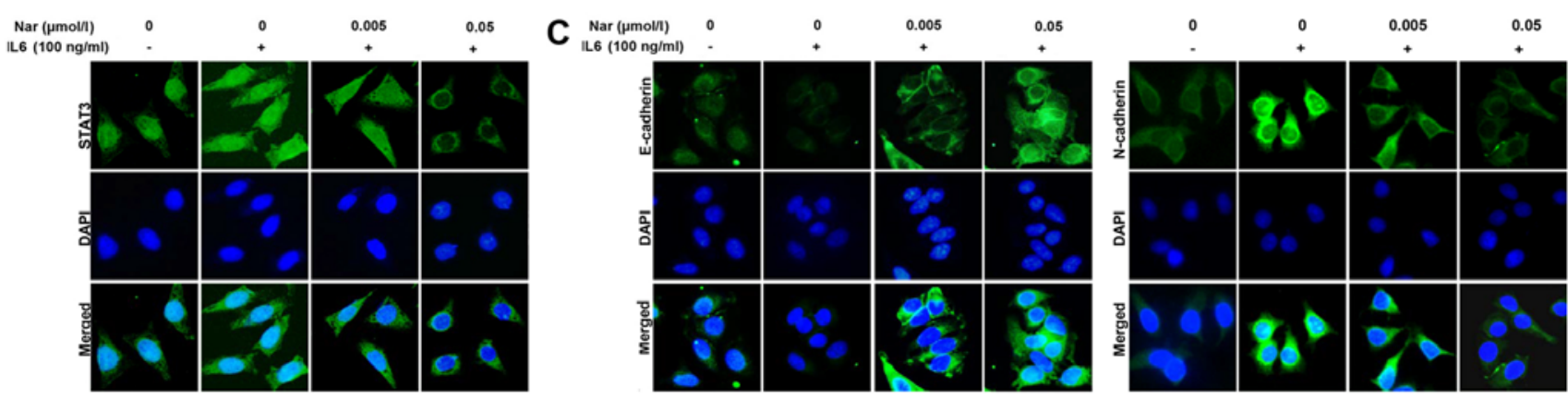

Figure 5. Narasin inhibits IL-6/STAT3 activation and epithelial-mesenchymal transition-related genes. (A) Narasin treatment blocked STAT3 phosphorylation with or without IL-6 stimulation in MCF-7 and T47D cells. (B) IF analysis of STAT3 expression in narasin-treated MCF-7 cells. (C) IF staining of E-cadherin and N-cadherin in narasin-treated MCF-7 cells. (D) Proposed model of the regulation and roles of the TGF- $\beta /$ SMAD3 and IL-6/STAT3 pathways in narasin-treated estrogen receptor-positive breast cancer cells. All results are representative of three independent experiments. Data are presented as the mean $\pm \mathrm{SD} .{ }^{*} \mathrm{P}<0.05,{ }^{* *} \mathrm{P}<0.01,{ }^{* * *} \mathrm{P}<0.001,{ }^{* * * *} \mathrm{P}<0.0001$. IF, immunofluorescence; $\mathrm{p}-$, phosphorylated.

of N-cadherin (Figs. 5C and S1G and H). In contrast, cells exposed to narasin at concentrations of 0.005 to $0.05 \mu \mathrm{mol} / 1$ showed a dose-dependent increase in E-cadherin expression and a decrease in $\mathrm{N}$-cadherin expression. These data indicated that narasin could inhibit EMT via TGF-3/SMAD3 and IL-6/STAT3 signaling, which suppresses the migratory and invasive abilities of $\mathrm{ER}^{+} \mathrm{BC}$ cells.

Narasin attenuates $E R^{+} B C$ metastasis. As commonly known, the lungs, brain and bones are the primary sites for BC metastasis (43), although nearly any tissue in the body can be metastasized by BC. In the present study, the widely used mouse left ventricle injection tumor metastasis model with MCF-7-Luc cells was used to investigate the potential inhibitory effects of narasin against BC metastasis. Following cancer cell injection, mice were treated with narasin for the duration of the experiment, and then a bioluminescence imaging assay was used to examine the effects of this treatment. As shown in Fig. 6A and B, intraperitoneal injection of narasin at doses of 0.5 and $1.5 \mathrm{mg} / \mathrm{kg}$ reduced brain and lung metastases, achieving 76.2 and $87.5 \%$ inhibition compared with the untreated control group on day 50 . Besides, no significant differences in body weight were detected among the three groups during treatment periods (Fig. 6C), which may indicate that the toxicity of narasin was low at the effective dose used to inhibit tumor growth. Besides, Fig. 6D shows that narasin effectively suppressed the phosphorylation of both p-SMAD2/3 and p-STAT3, without altering the total protein expression in the treatment groups as compared with the controls.

Narasin inhibits tumor growth and angiogenesis in $E R^{+}$ breast cancer. As the inhibition of primary BC tumor metastasis was observed following narasin treatment, the in vivo antitumor activities of narasin were investigated using the nude mouse subcutaneous xenograft model with MCF-7 cells. Intraperitoneal administration of narasin $(0.5$ and $1.5 \mathrm{mg} / \mathrm{kg}$, 14 days) significantly decreased tumor volume (Fig. 7A) and tumor weight (Fig. 7B) without noticeable weight changes (Fig. 7C). The percentage of tumor growth inhibition of narasin was 14.9 and $40.1 \%$ at 0.5 and $1.5 \mathrm{mg} / \mathrm{kg}$, respectively. When pulling the skin of each mouse back to expose an entire tumor, it was found that narasin-mediated suppression of tumor growth was associated with angiogenesis inhibition, as shown in the representative image from each group (Fig. 7D and E). The number of $\mathrm{CD} 31^{+}$endothelial cells was notably decreased in the high dose treatment group (Fig. S2). Additionally, the skin color and organs of the nude mouse were mostly normal, 
A

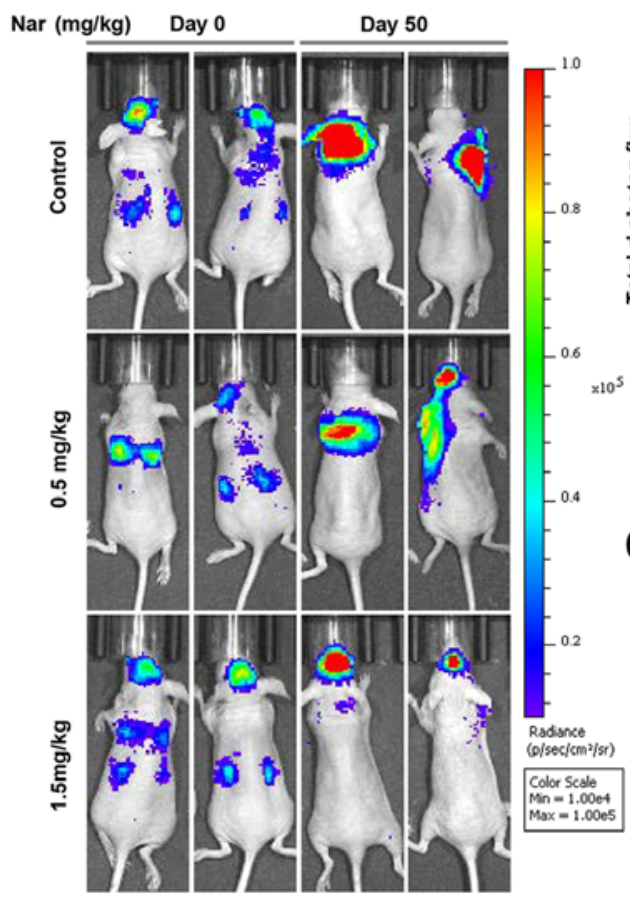

B

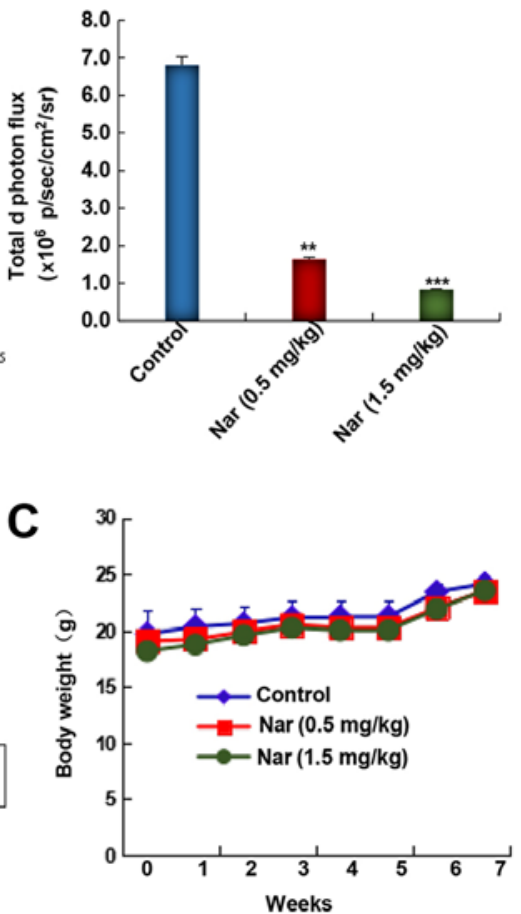

D

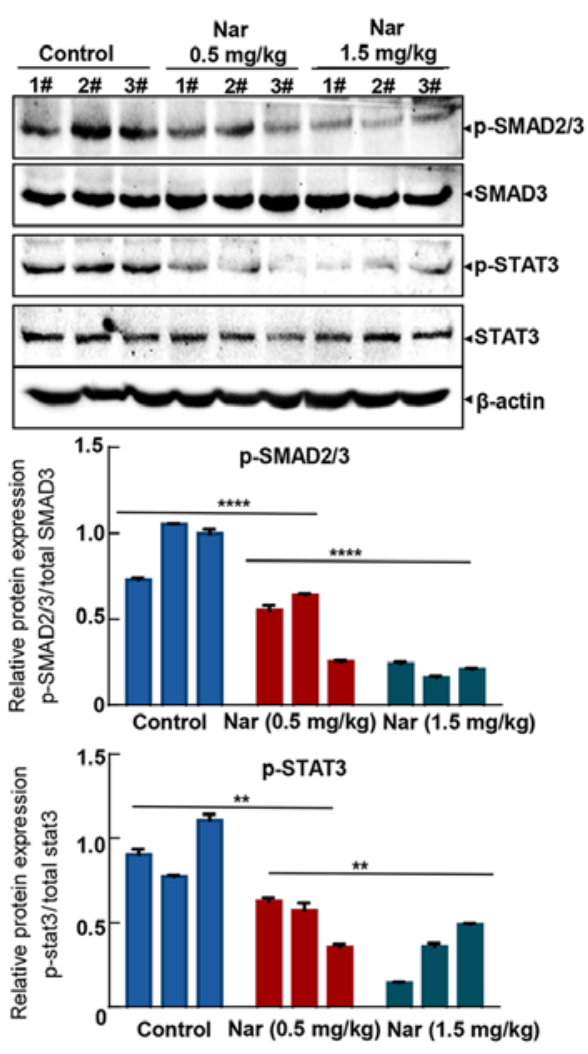

Figure 6. Therapeutic effects of narasin in the mouse left ventricle injection breast tumor metastasis model. (A) Representative bioluminescent imaging of mice injected with MCF-7-Luc cells in control and treatment groups. (B) Quantization of whole-body bioluminescence (total photon flux). ${ }^{* *} \mathrm{P}<0.01,{ }^{* * * *} \mathrm{P}<0.001 \mathrm{vs}$. the control group. (C) Narasin had no significant effect on the body weight of mice. (D) Western blotting was performed to determine the protein expression of p-SMAD2/3 and p-STAT3. A total of 3 tumors were randomly selected from different groups, and the experiments were repeated three times with consistent results. ${ }^{* *} \mathrm{P}<0.01,{ }^{* * * * *} \mathrm{P}<0.0001$. p-, phosphorylated.

as shown in Fig. 7E, which may suggest that the mice could tolerate the effective doses of narasin.

\section{Discussion}

The incidence and mortality of BC ranks first among female malignancies; $70-80 \%$ of patients with $\mathrm{BC}$ are diagnosed as $\mathrm{ER}^{+}(2)$. A number of studies have reported that the primary cause of death in $>90 \%$ of patients with BC is due to BC metastasis $(44,45)$. Tamoxifen was the first FDA-approved drug for $\mathrm{ER}^{+} \mathrm{BC}$ (12). Subsequently, a large number of drugs targeting $\mathrm{ER}^{+} \mathrm{BC}$ have been discovered and put into clinical use, such as everolimus and palbociclib. However, the current compounds used to treat $\mathrm{ER}^{+} \mathrm{BC}$ have different degrees of side effects and drug resistance, thus limiting their long-term use. There is an urgent need to identify and develop a drug that is safe, economical and immune to drug resistance to inhibit the metastasis of $\mathrm{ER}^{+} \mathrm{BC}$.

The present study reported a significant finding that narasin, a widely used agricultural antibiotic approved by the FDA, can act directly on tumor cells and inhibit various properties associated with $\mathrm{ER}^{+} \mathrm{BC}$, including tumor cell proliferation, migration and invasion, in vitro at lower concentrations. The MCF-7 and T47D ER ${ }^{+}$BC cell lines and the MDA-MB-231 triple-negative $\mathrm{BC}$ cell line were chosen as the in vitro models. The results showed that narasin had a significant dose-dependent inhibitory effect on the cell viability of BC cell lines, as aforementioned. The $\mathrm{IC}_{50}$ values of narasin in the MCF-7, T47D and MDA-MB-231 cell lines were 2.219, 3.562 and $11.76 \mu \mathrm{M}$, respectively. When further comparing the effects of narasin on $\mathrm{BC}$ cell migration and invasion, narasin at the much lower concentration of $0.005 \mu \mathrm{mol} / 1$ was found to significantly inhibit the migration and invasion of MCF-7 and T47D ER ${ }^{+} \mathrm{BC}$ cells; whereas, narasin inhibited MDA-MB-231 triple-negative BC cells at $2.5 \mu \mathrm{mol} / 1$. The inhibitory effects on cell migration and invasion continued to increase as the drug concentration was increased. A comparison of those two results suggested that narasin had a more pronounced inhibitory effect on the migration and invasion of the MCF-7 and T47D ER ${ }^{+} \mathrm{BC}$ cell lines, and that it is a potential target for candidate drugs to treat $\mathrm{ER}^{+} \mathrm{BC}$.

EMT plays a vital role in tumor progression, invasion and metastasis, which is a common molecular mechanism of tumor metastasis (7,46-49). During the process of EMT, tumor cells lose their epithelial cell characteristics and acquire mesenchymal cell characteristics, which gives them invasive abilities (7). Multiple signaling pathways, such as the TGF- $\beta /$ SMAD, IL-6/STAT3 and PI3K/AKT pathways, have been reported to promote EMT during tumor progression $(8,9,50)$. However, the specific molecular mechanism by which narasin inhibits $\mathrm{ER}^{+} \mathrm{BC}$ cell migration and invasion has not yet been revealed. In the present study, a microarray assay was used to screen and identify potential signaling pathways that contribute to the narasin-mediated inhibition on 
A

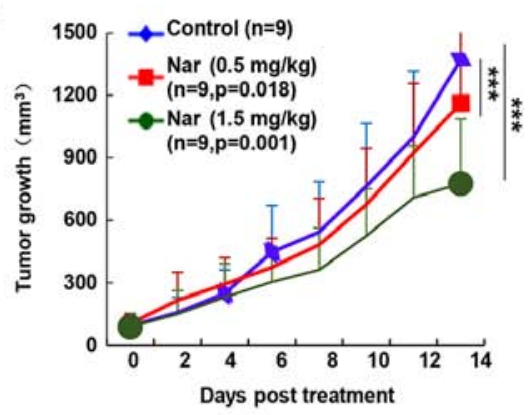

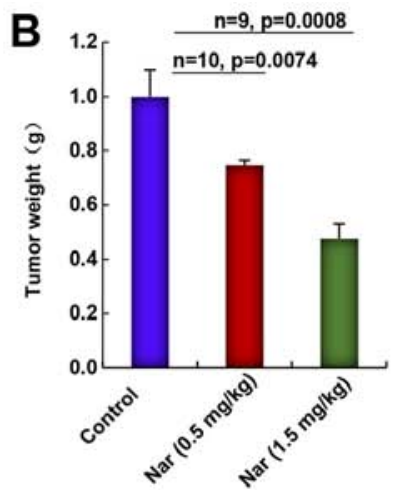

C

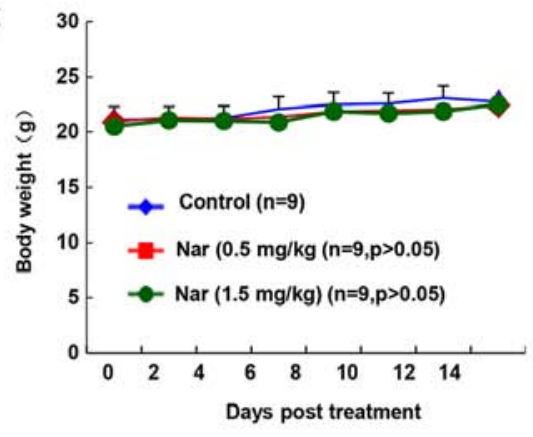

D

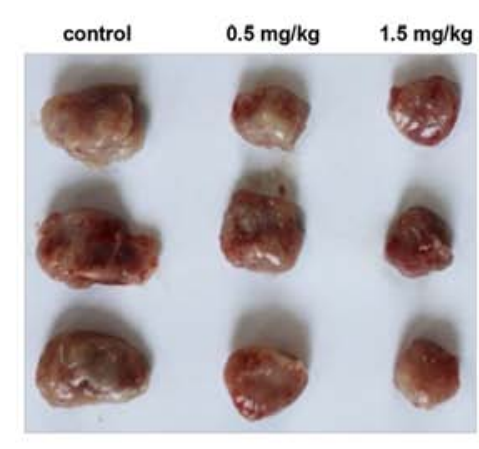

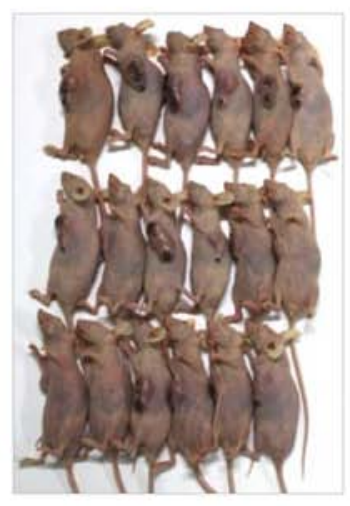
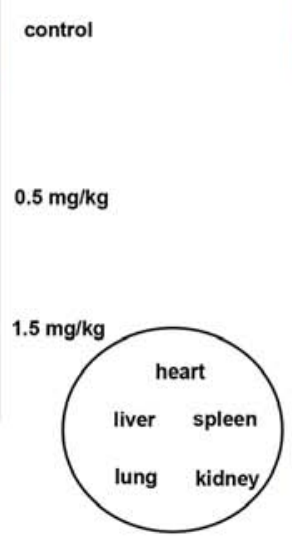

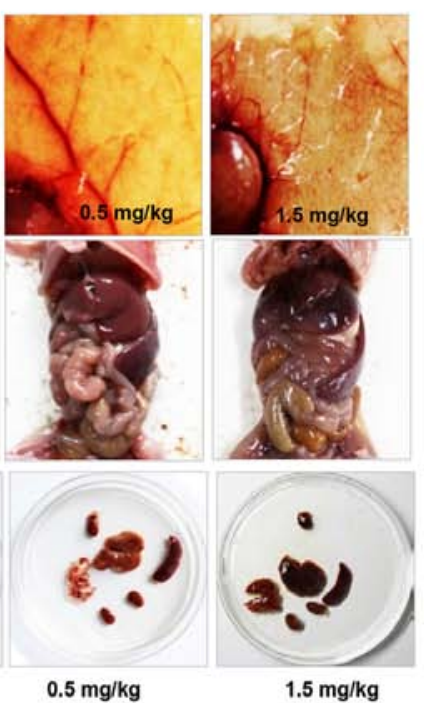

Figure 7. Narasin inhibits tumor growth and angiogenesis in the breast cancer subcutaneous tumor model. (A) Narasin inhibited tumor growth as indicated by the tumor volume. ${ }^{* * *} \mathrm{P}<0.001$. (B) Tumor weight in each group. (C) Mouse body weight was monitored once a day. (D) Images of tumor tissues in each group. (E) Images of the primary organs showed that there was no obvious toxicity 14 days after narasin treatment.

$\mathrm{ER}^{+} \mathrm{BC} \mathrm{MCF}-7$ metastasis and proliferation. The microarray analysis revealed that narasin could significantly block the TGF- $\beta$ /SMAD3 and IL-6/STAT3 signaling pathways, and the downstream signaling molecules in MCF-7. This result was confirmed by independent immunoblotting analysis. It is of note that several key genes associated with TGF- $\beta$, mTOR, JAK-STAT, p53 and HIF-1 signaling pathways were chosen, such as AKT, mTOR, S6K, JAK2, STAT3, p53, HIF-1 and $\mathrm{NF}-\kappa \mathrm{B}$. Among these signaling molecules, no notable changes were observed at the protein level of mTOR, S6K and HIF-1 in MCF-7 and T47D cell lines, as measured via western blotting in our preliminary experiments (data not shown). However, narasin markedly suppressed the phosphorylation of TGF- $\beta$-induced SMAD2/3 and IL-6-induced STAT3 phosphorylation. Therefore, the TGF- $\beta$ /SMAD3 and IL-6/STAT3 signaling pathways were selected for further study. It is hoped that we can address these points in our future studies due to the scope of the present study.

A number of studies have reported that TGF- $\beta$ binds to receptor 1 on the tumour cell membrane to activate the downstream SMAD2 and SMAD3 proteins, while p-SMAD2/3 proteins bind to cytoplasmic SMAD4 protein to form trimers. Following this, they translocate to the nucleus and combine with DNA to play a role in regulating the expression of related transcription factors (51), which leads to a reduction in the expression of E-cadherin and an increase in the expression of $\mathrm{N}$-cadherin and vimentin, thereby inducing EMT. The present results showed that narasin significantly inhibited SMAD2/3 activation and translocation into the nucleus with or without TGF- $\beta$ treatment in $\mathrm{ER}^{+} \mathrm{BC}$ cells. Using a cellular IF assay, it was also found that narasin increased E-cadherin expression and decreased $\mathrm{N}$-cadherin expression in a dose-dependent manner upon TGF- $\beta$ stimulation.

Studies have demonstrated that IL- 6 can increase the growth and metastasis of $\mathrm{ER}^{+} \mathrm{BC}$ by activating STAT3 phosphorylation and promoting EMT (9). In the present study, it was found that narasin inhibited the IL-6-induced activation of STAT3, as well as STAT3 translocation into the nucleus in MCF-7 and T47D BC cells at the effective concentrations (0.005 to $0.05 \mu \mathrm{mol} / 1)$. Using an IF assay, it was found that narasin dose-dependently increased E-cadherin expression and inhibited $\mathrm{N}$-cadherin expression induced by IL-6. The aforementioned results indicated that narasin may block EMT progression to suppress $\mathrm{ER}^{+} \mathrm{BC}$ metastasis via the TGF- $\beta$ /SMAD3 and IL-6/STAT3 pathways. Recent studies revealed that the IL-6/STAT3 signaling pathway was required for the TGF- $\beta$-induced EMT process in lung cancer cells $(52,53)$, and STAT3 could selectively interact with SMAD3 to antagonize TGF- $\beta$ signalling $(52,53)$. There may be crosstalk between the IL-6/STAT3 and TGF- $\beta / \mathrm{p}-\mathrm{SMAD} 3$ 
signaling pathway in certain conditions $(52,53)$, indicating that dual suppression of the TGF- $\beta /$ SMAD3 and IL-6/STAT3 pathways could inhibit the progression of EMT more effectively.

Numerous chemotherapeutic drugs cannot penetrate the blood-brain barrier, resulting in insufficient drug concentrations at the brain lesion and therapeutic resistance to brain metastases. In the present report, daily treatment with 0.5 and $1.5 \mathrm{mg} / \mathrm{kg}$ narasin was effective in reducing brain and lung tumor metastasis, as well as tumor growth in mouse tumor models, without inducing any apparent toxicity. Collectively, these findings indicated that narasin is a novel inhibitor of $\mathrm{ER}^{+} \mathrm{BC}$ cells and may be a promising anticancer drug candidate. However, further studies are needed to substantiate this hypothesis.

\section{Acknowledgements}

The authors would like to thank Professor Fen Wang (Center for Translational Cancer Research, Institute of Biosciences and Technology, Texas A\&M, Texas, USA) for their help with the English.

\section{Funding}

The present study was supported by grants from the National Natural Science Foundation of China (grant nos. 81560485, 816660500 and 81760525), the West China Top Class Discipline Project in Basic Medical Sciences, Ningxia Medical University (grant nos. NXYLXK2017B07 and NXYLXK2017A05); the Ningxia Municipal Education Commission (grant no. NGY2015094) and the Natural Science Foundation of Ningxia (grant no. NZ16142).

\section{Availability of data and materials}

All data generated or analyzed during this study are included in this published article.

\section{Authors' contributions}

JC and TL conceived and designed the study. XH, NL, BL and JL performed the experiments. JC, WY and ZM analysed the data. JC, TL and WY provided administrative, technical or material support. JC and XH wrote the manuscript. All authors read and approved the final manuscript.

\section{Ethics approval and consent to participate}

All mouse studies were performed according to animal protocols approved by the Institutional Animal Care and Use Committee of Ningxia Medical University (Yinchuan, China; approval no. 20170006).

\section{Patient consent for publication}

Not applicable.

\section{Competing interests}

The authors declare that they have no competing interests.

\section{References}

1. Bray F, Ferlay J, Soerjomataram I, Siegel RL, Torre LA and Jemal A: Global cancer statistics 2018: GLOBOCAN estimates of incidence and mortality worldwide for 36 cancers in 185 countries. CA Cancer J Clin 68: 394-424, 2018.

2. Reiner $\mathrm{T}$ and Barrios $\mathrm{CH}$ : Optimal management of hormone receptor positive metastatic breast cancer in 2016. Ther Adv Med Oncol 7: 304-320, 2015

3. Vuong D, Simpson PT, Green B, Cummings MC and Lakhani SR: Molecular classification of breast cancer. Virchows Arch 465: 1-14, 2014.

4. Mikula-Pietrasik J, Uruski P, Tykarski A and Ksiazek K: The peritoneal 'soil' for a cancerous 'seed': A comprehensive review of the pathogenesis of intraperitoneal cancer metastases. Cell Mol Life Sci 75: 509-525, 2018.

5. Riggi N, Aguet M and Stamenkovic I: Cancer metastasis: A reappraisal of its underlying mechanisms and their relevance to treatment. Annu Rev Pathol 13: 117-140, 2018.

6. Lambert AW, Pattabiraman DR and Weinberg RA: Emerging biological principles of metastasis. Cell 168: 670-691, 2017.

7. Brabletz T, Kalluri R, Nieto MA and Weinberg RA: EMT in cancer. Nat Rev Cancer 18: 128-134, 2018.

8. Chiu HC, Li CJ, Yiang GT, Tsai AP and Wu MY: Epithelial to mesenchymal transition and cell biology of molecular regulation in endometrial carcinogenesis. J Clin Med 8: 439, 2019.

9. Wang B, Liu T, Wu JC,Luo SZ, Chen R,Lu LG and Xu MY: STAT3 aggravates TGF- $\beta 1$-induced hepatic Epithelial-to-mesenchymal transition and migration. Biomed Pharmacother 98: 214-221, 2018.

10. Akhurst RJ and Derynck R: TGF-beta signaling in cancer-a Double-edged sword. Trends Cell Biol 11 (Suppl): S44-S51, 2001.

11. Henke BR and Heyer D: Recent advances in estrogen receptor modulators. Curr Opin Drug Discov Devel 8: 437-448, 2005.

12. Elkak AE and Mokbel K: Pure antiestrogens and breast cancer. Curr Med Res Opin 17: 282-289, 2001.

13. Younus $\mathbf{J}$ and Vandenberg TA: A practical overview of aromatase inhibitors in postmenopausal women with hormone receptor-positive breast cancer. Bull Cancer 92: E39-E44, 2005.

14. Braga S: Resistance to targeted therapies in breast cancer. Methods Mol Biol 1395: 105-136, 2016.

15. Lumachi F, Santeufemia DA and Basso SM: Current medical treatment of estrogen receptor-positive breast cancer. World J Biol Chem 6: 231-239, 2015.

16. Riddell FG: Structure, conformation, and mechanism in the membrane transport of alkali metal ions by ionophoric antibiotics. Chirality 14: 121-125, 2002.

17. Gupta PB, Onder TT, Jiang G, Tao K, Kuperwasser C, Weinberg RA and Lander ES: Identification of selective inhibitors of cancer stem cells by high-throughput screening. Cell 138: 645-659, 2009.

18. Markowska A, Kaysiewicz J, Markowska J and Huczynski A: Doxycycline, salinomycin, monensin and ivermectin repositioned as cancer drugs. Bioorg Med Chem Lett 29: 1549-1554, 2019.

19. Jiang J, Li H, Qaed E, Zhang J, Song Y, Wu R, Bu X, Wang Q and Tang Z: Salinomycin, as an autophagy modulator-a new avenue to anticancer: A review. J Exp Clin Cancer Res 37: 26, 2018.

20. Cybulski W, Radko L and Rzeski W: Cytotoxicity of monensin, narasin and salinomycin and their interaction with silybin in HepG2, LMH and L6 cell cultures. Toxicol In Vitro 29: 337-344, 2015.

21. Miller SC, Huang R, Sakamuru S, Shukla SJ, Attene-Ramos MS, Shinn P, Van Leer D, Leister W, Austin CP and Xia M: Identification of known drugs that act as inhibitors of NF-kappaB signaling and their mechanism of action. Biochem Pharmacol 79: 1272-1280, 2010

22. Yoon MJ, Kang YJ, Kim IY, Kim EH, Lee JA, Lim JH, Kwon TK and Choi KS: Monensin, a polyether ionophore antibiotic, overcomes TRAIL resistance in glioma cells via endoplasmic reticulum stress, DR5 upregulation and c-FLIP downregulation. Carcinogenesis 34: 1918-1928, 2013.

23. Chen J, Wang J, Lin L, He L, Wu Y, Zhang L, Yi Z, Chen Y, Pang $X$ and Liu M: Inhibition of STAT3 signaling pathway by nitidine chloride suppressed the angiogenesis and growth of human gastric cancer. Mol Cancer Ther 11: 277-287, 2012.

24. Li T, Liu X, Shen Q, Yang W, Huo Z, Liu Q, Jiao H and Chen J: Salinomycin exerts anti-angiogenic and anti-tumorigenic activities by inhibiting vascular endothelial growth factor receptor 2-mediated angiogenesis. Oncotarget 7: 26580-26592, 2016. 
25. Kanehisa M, Sato Y, Furumichi M, Morishima K and Tanabe M: New approach for understanding genome variations in KEGG. Nucleic Acids Res 47: D590-D595, 2019.

26. Kanehisa M: Toward understanding the origin and evolution of cellular organisms. Protein Sci 28: 1947-1951, 2019.

27. Kanehisa M and Goto S: KEGG: Kyoto encyclopedia of genes and genomes. Nucleic Acids Res 28: 27-30, 2000.

28. Galili T, O'Callaghan A, Sidi J and Sievert C: Heatmaply: An $\mathrm{R}$ package for creating interactive cluster heatmaps for online publishing. Bioinformatics 34: 1600-1602, 2018

29. Amaskos C, Garmpi A, Nikolettos K, Vavourakis M, Diamantis E, Patsouras A, Farmaki P, Nonni A, Dimitroulis D, Mantas D, et al: Triple-negative breast cancer: The progress of targeted therapies and future tendencies. Anticancer Res 39: 5285-5296, 2019.

30. Van Themsche C, Parent S, Leblanc V, Descôteaux C, Simard AM, Bérubé G and Asselin E: VP-128, a novel oestradiol-platinum(II) hybrid with selective anti-tumour activity towards hormone-dependent breast cancer cells in vivo. Endocr Relat Cancer 16: 1185-1195, 2009.

31. Shi JF, Yang N, Ding HJ, Zhang JX, Hu ML, Leng Y, Han X and Sun YJ: Ra directly activated the MDR1 transcription to increase paclitaxel-resistance of ER $\alpha$-positive breast cancer cells in vitro and in vivo. Int $\mathrm{J}$ Biochem Cell Biol 53: 35-45, 2014.

32. Márquez-Garbán DC, Deng G, Comin-Anduix B, Garcia AJ, Xing Y, Chen HW, Cheung-Lau G, Hamilton N, Jung ME and Pietras RJ: Antiestrogens in combination with immune checkpoint inhibitors in breast cancer immunotherapy. J Steroid Biochem Mol Biol 193: 105415, 2019.

33. Wang J, Hu K, Guo J, Cheng F, Lv J, Jiang W, Lu W, Liu J, Pang $X$ and Liu M: Suppression of KRas-mutant cancer through the combined inhibition of KRAS with PLK1 and ROCK. Nat Commun 7: 11363, 2016.

34. Itoh S, Itoh F, Goumans MJ and Ten Dijke P: Signaling of transforming growth factor-beta family members through Smad proteins. Eur J Biochem 267: 6954-6967, 2000.

35. Shi Y and Massagué J: Mechanisms of TGF-beta signaling from cell membrane to the nucleus. Cell 113: 685-700, 2003.

36. Mehra A and Wrana JL: TGF-beta and the Smad signal transduction pathway. Biochem Cell Biol 80: 605-622, 2002.

37. Heldin $\mathrm{CH}$, Landström $\mathrm{M}$ and Moustakas A: Mechanism of TGF-beta signaling to growth arrest, apoptosis, and epithelial-mesenchymal transition. Curr Opin Cell Biol 21: 166-176, 2009.

38. Dumont $\mathrm{N}$ and Arteaga CL: Targeting the TGF beta signaling network in human neoplasia. Cancer Cell 3: 531-536, 2003.

39. Kandasamy M, Reilmann R, Winkler J, Bogdahn U and Aigner L: Transforming growth factor-beta signaling in the neural stem cell niche: A therapeutic target for Huntington's disease. Neurol Res Int 2011: 124256, 2011.

40. Liu S, Chen S and Zeng J: TGF- $\beta$ signaling: A complex role in tumorigenesis (Review). Mol Med Rep 17: 699-704, 2018.
41. Lucarelli P, Schilling M, Kreutz C, Vlasov A, Boehm ME, Iwamoto N, Steiert B, Lattermann S, Wasch M, Stepath M, et al: Resolving the combinatorial complexity of smad protein complex formation and its link to gene expression. Cell Syst 6: 75-89.e11, 2018.

42. Lou W, Chen Y, Zhu KY, Deng H, Wu T and Wang J: Polyphyllin I overcomes EMT-associated resistance to erlotinib in lung cancer cells via IL-6/STAT3 pathway inhibition. Biol Pharm Bull 40: 1306-1313, 2017.

43. Akram M, Iqbal M, Daniyal $M$ and Khan AU: Awareness and current knowledge of breast cancer. Biol Res 50: 33, 2017.

44. Majumder A, Singh M and Tyagi SC: Post-menopausal breast cancer: From estrogen to androgen receptor. Oncotarget 8: 102739-102758, 2017

45. Guo W, Zhang S and Liu S: Establishment of a novel orthotopic model of breast cancer metastasis to the lung. Oncol Rep 33: 2992-2998, 2015.

46. Ghulam J, Stuerken C, Wicklein D, Pries R, Wollenberg B and Schumacher U: Immunohistochemical analysis of transcription factors and markers of Epithelial-mesenchymal transition (EMT) in human tumors. Anticancer Res 39: 5437-5448, 2019.

47. Li L, Zhang S, Li H and Chou H: FGFR3 promotes the growth and malignancy of melanoma by influencing EMT and the phosphorylation of ERK, AKT, and EGFR. BMC Cancer 19: 963 , 2019.

48. Si L, Fu J, Liu W, Hayashi T, Nie Y, Mizuno K, Hattori S, Fujisaki H, Onodera S and Ikejima T: Silibinin inhibits migration and invasion of breast cancer MDA-MB-231 cells through induction of mitochondrial fusion. Mol Cell Biochem 463: 189-201, 2020.

49. Zhang LN, Huang YH and Zhao L: Fusion of macrophages promotes breast cancer cell proliferation, migration and invasion through activating epithelial-mesenchymal transition and Wnt/ $\beta$-catenin signaling pathway. Arch Biochem Biophys 676: 108137,2019

50. Xu J, Lamouille S and Derynck R: TGF-beta-induced epithelial to mesenchymal transition. Cell Res 19: 156-172, 2009.

51. Moustakas A, Souchelnytskyi S and Heldin CH: Smad regulation in TGF-beta signal transduction. J Cell Sci 114: 4359-4369, 2001.

52. Wang G, Yu Y, Sun C, Liu T, Liang T, Zhan L, Lin X and Feng XH: STAT3 selectively interacts with Smad3 to antagonize TGF- $\beta$ signalling. Oncogene 35: 4388-4398, 2016.

53. Itoh Y, Saitoh M and Miyazawa K: Smad3-STAT3 crosstalk in pathophysiological contexts. Acta Biochim Biophys Sin (Shanghai) 50: 82-90, 2018

This work is licensed under a Creative Commons Attribution-NonCommercial-NoDerivatives 4.0 International (CC BY-NC-ND 4.0) License. 